\title{
A formação superior em gastronomia: análise descritiva das dissertações de mestrado produzidas no Brasil 1
}

\author{
Higher education in gastronomy: descriptive analysis of dissertations \\ produced in Brazil
}

\section{La formación superior en gastronomía: análisis descriptivo de las tesis producidas en Brasil}

\section{Maria Henriqueta Sperandio Garcia Gimenes-Minasse ${ }^{2}$}

\begin{abstract}
Resumo: Este artigo tem como objetivo geral conhecer o quadro atual das pesquisas realizadas no Brasil em nível de pós-graduação (mestrado) sobre formação profissional em Gastronomia. Para tanto foi realizada revisão bibliográfica, pesquisa documental e análise descritiva das dissertações sobre o tema defendidas no país até o final de 2012. Foram analisadas: as instituições de ensino e os programas de pós-graduação cursados; as palavras-chave indicadas; o perfil dos pesquisadores (graduação e experiência profissional); objetivos gerais e a abrangência da pesquisa realizada; metodologias utilizadas. Os principais resultados apontam: a predominância de pesquisas realizadas na cidade de São Paulo, pesquisadores familiarizados com a graduação tecnológica em Gastronomia (do ponto de vista da formação e da atuação profissional), predominância de temáticas voltadas ao processo de ensino-aprendizagem, prevalência de pesquisas de caráter qualitativo, e ocorrência de descrição muito sucinta da metodologia empregada em alguns trabalhos.
\end{abstract}

Palavras-chave: Gastronomia. Formação superior. Dissertações. Brasil.

Abstract: The general purpose of this article is to assess the current situation of researches conducted in Brazil at the post-graduation level (masters degree) on professional training in Gastronomy. We have conducted literature review, documental research and descriptive analysis of dissertations defended on the subject matter in Brazil until the end of 2012. We have analyzed: the educational institutions and post graduations programs involved; keywords shown in the dissertations; researchers' profile (major graduation and professional experience); general objectives and the research's scope; methodologies used. The main results show: the predominance of researches conducted in the city of São Paulo, researchers with some degree of experience in Gastronomy (with respect to training and professional practice), predominance of researches focused on the learning/teaching process, predominance of qualitative research, and the lack of detailed description of methodologies used in some researches.

Keywords: Higher education. Gastronomy. Master dissertations. Brazil.

1 Versão expandida e revisada do artigo "A formação superior em gastronomia - uma reflexão preliminar a partir das dissertações de mestrado defendidas sobre a temática até dezembro de 2012", apresentado durante o Seminário Anptur 2013, em Caxias do Sul, Brasil.

2 Bacharel em Turismo, Mestre em Sociologia de Doutora em História pela Universidade Federal do Paraná.

Professora Adjunto III na Universidade Federal de São Carlos - Campus Sorocaba. Email:

mariegimenes@gmail.com. 
Resumen: Este artículo tiene como objetivo general conocer la realidad de las investigaciones realizadas en Brasil en nivel de posgrado acerca de la formación profesional en Gastronomía. Por lo tanto, se hizo una revisión de la bibliografía, investigación documental y análisis descriptivo de las tesis leídas en Brasil hasta el final del 2012. Se han analizado: las instituciones de enseñanza y los programas de posgrado; las palabras-clave enseñadas; el perfil de los investigadores (formación y experiencia profesional); objetivos generales y el alcance de las investigaciones, bien como la metodología empleada. Los principales resultados se refieren a: el predominio de investigaciones llevadas a cabo en la ciudad de São Paulo, investigadores familiarizados con la formación técnica en gastronomía (desde un punto de vista de la formación y actuación profesional), predominio de temas orientados a un proceso de enseñanzaaprendizaje, prevalencia de investigaciones de carácter cualitativo y la ocurrencia de descripciones muy breves de la metodología empleada en algunos estudios.

Palavras chave: Gastronomía. Formación superior. Tesis. Brasil.

\section{INTRODUÇÃO}

A gastronomia é tema recorrente nos dias de hoje: está em revistas especializadas, em livros com os mais diferentes enfoques, em blogs e sites, em programas de televisão, em filmes, em jogos de celular e de tabuleiro, em guias específicos, dentre outros. Esta onipresença deve-se à mudança das representações relacionadas à comida e aos espaços de comer fora, criando um mercado que se expande cada vez mais buscando satisfazer os mais diferentes perfis de clientes. Ela torna-se, neste contexto, uma possibilidade de lazer e também de uma carreira percebida por muitos como glamorosa por conta da atenção recebida pela mídia em geral.

Como resultado, o interesse pela formação de nível superior na área também se ampliou. Em 2008, segundo matéria publicada na Revista Prazeres da Mesa, existiam 79 cursos superiores em gastronomia, sendo 74 cursos de tecnologia e 5 bacharelados (Kissman; Rocha, 2008). Em 2012, segundo dados disponibilizados pelo E-MEC (MEC, 2012), os cursos superiores em gastronomia já totalizavam 129 (8 cursos de bacharelado e 121 cursos tecnológicos). Esta expansão bastante rápida, considerando que os primeiros cursos surgiram em 1999, tem esboçado uma nova dinâmica de mercado, com a formação de centenas de profissionais com um novo perfil e a própria exigência de qualificação acadêmica daqueles que desejam atuar como docentes nestes cursos.

Esta nova realidade tem despertado o interesse de alguns pesquisadores, que buscam conhecer e compreender diferentes aspectos destas novas dinâmicas. Dentre as pesquisas já realizadas, destacam-se as dissertações de mestrado, iniciativas que procuram tratar questões de maneira mais aprofundada. Fruto de uma pesquisa de caráter exploratório-descritivo, este artigo tem como objetivo geral conhecer o quadro atual das pesquisas realizadas no Brasil em nível de pós-graduação (mestrado) sobre formação profissional em gastronomia. São objetivos específicos deste trabalho: identificar as instituições de ensino e os programas de pós-graduação em que foram realizadas as dissertações; identificar as palavras-chave indicadas pelos autores; caracterizar o perfil dos pesquisadores a partir da identificação da formação base do pesquisador e sua atuação profissional no período de realização do mestrado; analisar dos objetivos gerais das dissertações; caracterizar a abrangência da pesquisa realizada; analisar as metodologias utilizadas. 
Para a realização desta pesquisa foi realizada uma revisão bibliográfica, uma pesquisa documental (dos instrumentos técnico-legais brasileiros sobre cursos superiores em gastronomia) e uma análise descritiva das dissertações sobre o tema defendidas no país até o final de 2012. A metodologia baseou-se principalmente nos trabalhos de Rejowski (2010) e Lima e Rejowski (2011).

O primeiro trabalho analisou a produção científica em Turismo com bases em teses acadêmicas defendidas entre 1990 e 2005 no país. Como elementos de análise desta pesquisa foram estabelecidos: o número de registro no banco de teses da CAPES (Coordenação de Aperfeiçoamento Pessoal de Nível Superior), título, tipo (doutorado ou livre docência), ano do documento, orientador, instituição, programa, resumo, descritores (palavras-chave) (Rejowski, 2010). O segundo realizou um mapeamento da produção científica sobre ensino superior no Brasil, tendo como janela cronológica 2000-2009 e os seguintes elementos de análise: autor, título, resumo, tipo (mestrado ou doutorado), ano, orientador, programa, instituição, descritores (palavras-chave) e locais de estudo. As pesquisadoras levantaram ainda os seguintes dados dos autores de cada trabalho na plataforma Lattes do Conselho Nacional de Desenvolvimento Científico e Tecnológico (CNPq): nome, sexo, formação acadêmica (graduação) e atuação profissional (Lima; Rejowski, 2011).

Nesta pesquisa realizou-se um levantamento on line de dissertações de mestrado defendidas no Brasil até dezembro de 2012 e que possuíam como tema a formação superior em gastronomia. Foram consideradas as dissertações localizadas a partir de uma busca que teve como referência as palavras-chave "gastronomia", "formação superior" e "ensino" e cujo texto integral estava disponível na internet. Os dados foram obtidos a partir da leitura do texto integral das dissertações e subsidiaram a elaboração de quadros-síntese com as informações pertinentes (alguns destes quadros são apresentados neste trabalho), e ainda foi realizada a consulta aos currículos dos autores disponíveis no Sistema LATTES/CNPq, buscando identificar sua formação base (graduação) e atuação profissional durante o período de realização do mestrado.

\section{REFLEXÕES SOBRE A FORMAÇÃO SUPERIOR EM GASTRONOMIA NO BRASIL}

A formação profissional relacionada à Gastronomia foi introduzida no Brasil na década de 1950 pelo Serviço Nacional de Aprendizagem Comercial - SENAC. Embora este quadro tenha evoluído com a criação de diversos cursos técnicos e de curta duração objetivando a formação de mão de obra para as áreas de salão e cozinha, a trajetória dos cursos superiores em gastronomia teve início apenas décadas depois.

Conforme registram Rubim e Rejowski (2013), em 1999 surgiram os primeiros cursos superiores em gastronomia no Brasil: o Curso de bacharelado em Turismo com habilitação em Gastronomia na Universidade do Sul de Santa Catarina (Florianópolis, SC); o Curso superior sequencial em Gastronomia da Universidade Anhembi-Morumbi (São Paulo, SP); os Cursos superiores em Gastronomia (graduação e sequencial) na Universidade do Vale do Itajaí (Itajaí, SC). O SENAC, que desde 1989 oferecia o curso de tecnologia em hotelaria e vários cursos na área de 
restauração, iniciou o curso de tecnologia em gastronomia no Hotel Escola Águas de São Pedro (Águas de São Pedro, SP) apenas no ano 2000.

No âmbito da Gastronomia os cursos tecnológicos, concebidos para propiciar qualificação profissional que permita uma rápida inserção no mercado de trabalho, predominam. A abertura destes cursos se deu em resposta às necessidades do mercado de trabalho e seguiu os parâmetros legais estabelecidos pela Lei de Diretrizes e Bases da Educação n. 9.394 publicada em 1996 - LDB 1996, que rege o ensino de graduação (nas modalidades tecnológico, bacharelado e licenciatura), de pós-graduação (nos níveis mestrado e doutorado) e também os cursos sequenciais. O Parecer CNE/CES n. 436 de 2001 sintetiza a concepção de educação tecnológica inserida na LDB 1996:

[...] a educação profissional é concebida como integrada às diferentes formas de educação, ao trabalho, à ciência e à tecnologia, conduzindo ao permanente desenvolvimento de aptidões para a vida produtiva. (Art. 39 - LDB). Ela é acessível ao aluno matriculado ou egresso do ensino fundamental, médio e superior, bem como ao trabalhador em geral, jovem ou adulto. (Parágrafo único - Art.39 LDB), desenvolvendo-se em articulação com o ensino regular ou por diferentes formas de educação continuada, em instituições especializadas ou no ambiente de trabalho. (Art. 40 - LDB). 0 conhecimento adquirido, inclusive no trabalho, poderá ser objeto de avaliação, reconhecimento e certificação para prosseguimento ou conclusão de estudos (Art. 41 LDB)(CNE/CES, 2001, p. 2).

Estes cursos possuem especificidades: tem duração menor em relação aos cursos de bacharelado, privilegiam abordagens de caráter mais prático e não possuem diretrizes curriculares específicas. São regidos pelas Diretrizes Curriculares Nacionais (DCN) publicadas em dezembro de 2002, que caracteriza o conjunto geral dos cursos de tecnológicos ofertados no país. O quadro 1 sintetiza os principais instrumentos técnico-legais que regulam esta oferta: 
Quadro 1 - Síntese dos instrumentos técnico-legais que regem os cursos tecnológicos no brasil

\begin{tabular}{|c|c|}
\hline Instrumento legal & Conteúdos principais \\
\hline $\begin{array}{l}\text { Parecer } \mathrm{CNE}^{3} / \mathrm{CES}^{4} \text { n. 436/2001, } \\
\text { aprovado em } 02 \text { de abril de } 2001\end{array}$ & $\begin{array}{l}\text { Estabelece: a natureza da formação em tecnologia como } \\
\text { pertencente ao quadro da educação superior; as condições de } \\
\text { abertura e funcionamento destes cursos; o perfil dos mesmos em } \\
\text { relação ao seu público alvo e características da formação } \\
\text { oferecida; duração e estruturação dos cursos em questão. Fixa } \\
\text { aos cursos tecnológicos de Gastronomia no âmbito da área } \\
\text { profissional Turismo e Hospitalidade e estabelece como carga } \\
\text { horária mínima exigida } 1.600 \text { horas. }\end{array}$ \\
\hline $\begin{array}{l}\text { Parecer } \mathrm{CNE} / \mathrm{CP}^{5} \text { n. } 29 / 2002 \text {, aprovado } \\
\text { em } 03 \text { de dezembro de } 2002\end{array}$ & $\begin{array}{l}\text { Apresenta a evolução histórica da educação tecnológica no Brasil; } \\
\text { caracteriza a formação tecnológica em termos de natureza, } \\
\text { densidade, demanda, tempo de formação e perfil; apresenta os } \\
\text { princípios norteadores e a organização da educação tecnológica } \\
\text { no país. }\end{array}$ \\
\hline $\begin{array}{l}\text { Resolução CNE/CP n. 3/2002, } \\
\text { aprovada em } 18 \text { de dezembro de } 2002\end{array}$ & $\begin{array}{l}\text { Institui as Diretrizes Curriculares Nacionais Gerais para a } \\
\text { organização e o funcionamento dos cursos superiores de } \\
\text { tecnologia no país, especificando as informações que devem fazer } \\
\text { parte do Projeto Pedagógico dos cursos em questão. }\end{array}$ \\
\hline $\begin{array}{l}\text { Parecer CNE/CP n. 6/2006, aprovado } \\
\text { em } 6 \text { de abril de } 2006\end{array}$ & $\begin{array}{l}\text { Estabelece diferenciações e limites na relação entre formação } \\
\text { acadêmica e exercício profissional de atividades correlatas a } \\
\text { profissões regulamentadas [não se aplica à Gastronomia] }\end{array}$ \\
\hline $\begin{array}{l}\text { Parecer CNE/CES n. 277/2006, } \\
\text { aprovado em } 7 \text { de dezembro de } 2006\end{array}$ & $\begin{array}{l}\text { Apresenta a nova forma de organização da Educação Profissional } \\
\text { e Tecnológica de graduação em eixos de atuação mais compactos. } \\
\text { Fixa os cursos tecnológicos de Gastronomia no âmbito da área } \\
\text { profissional Hospitalidade e Lazer. . }\end{array}$ \\
\hline $\begin{array}{l}\text { Parecer CNE/CES n. 19/2008, } \\
\text { aprovado em } 31 \text { de janeiro de } 2008\end{array}$ & $\begin{array}{l}\text { Em resposta à solicitação da Faculdade de Tecnologia de Minas } \\
\text { Gerais estabelece parâmetros para o aproveitamento de } \\
\text { competências profissionais no âmbito dos cursos tecnológicos. }\end{array}$ \\
\hline $\begin{array}{l}\text { Parecer CNE/CES n. 239/2008, } \\
\text { aprovado em } 6 \text { de novembro de } 2008\end{array}$ & $\begin{array}{l}\text { Caracteriza o que são atividades acadêmicas complementares e } \\
\text { estabelece seus limites de carga horária para os cursos } \\
\text { tecnológicos. }\end{array}$ \\
\hline
\end{tabular}

Fonte: a autora (2013)

Deve-se destacar o parecer CNE $^{6} /$ CES $^{7}$ n. 436/2001 que estabeleceu a formação em Gastronomia na área de atuação profissional Turismo e Hospitalidade, assim descrita:

\footnotetext{
${ }^{3}$ CNE: Conselho Nacional de Educação

${ }^{4}$ CES: Câmara de Educação Superior

${ }^{5} \mathrm{CP}$ : Conselho Pleno do Conselho Nacional de Educação

${ }^{6}$ CNE: Conselho Nacional de Educação
} 
Compreende atividades, interrelacionadas ou não, referentes à oferta de produtos e à prestação de serviços turísticos e de hospitalidade. Os serviços turísticos incluem o agenciamento e operação, o guiamento, a promoção do turismo, e a organização e realização de eventos de diferentes tipos e portes. Os serviços de hospitalidade incluem os de hospedagem e os de alimentação. Os de hospedagem são prestados em hotéis e outros meios, como colônias de férias, albergues, condomínios residenciais e de lazer, instituições esportivas, escolares, militares, de saúde, acampamentos, navios, coletividades, abrigos para grupos especiais. Os serviços de alimentação são prestados em restaurantes, bares e outros meios, como empresas, escolas, clubes, parques, aviões, navios, trens, ou ainda em serviços de bufês, "caterings", entregas diretas, distribuição em pontos de venda. Estas atividades são desenvolvidas num processo que inclui o planejamento, a promoção e venda e o gerenciamento da execução. (CNE/CES, 2001, p.23). [grifo nosso].

Os serviços de alimentação eram então apontados como pertencentes ao contexto da hospitalidade, e o texto legal preocupa-se em especificar os locais de atuação profissional, enfatizando também que tal formação foge ao escopo meramente operacional, na medida em que se dedica a ações de planejamento, promoção e venda e gerenciamento das atividades relacionadas. O Parecer CNE/CES n. 277/2006, cuja proposta foi a de sintetizar os eixos de áreas profissionais em relação ao Parecer de 2001, fixou os cursos de Gastronomia (juntamente com os cursos de Eventos, Gestão do Turismo, Gestão Desportiva e de Lazer, e de Hotelaria) no eixo Hospitalidade e Lazer, que corresponde à seguinte descrição:

Compreende tecnologias relacionadas aos processos de recepção, entretenimento e interação. Abrange os processos tecnológicos de planejamento, organização, operação e avaliação de produtos e serviços inerentes à hospitalidade e ao lazer. As atividades compreendidas nesse eixo referem-se ao lazer, relações sociais, turismo, eventos e gastronomia, integradas ao contexto das relações humanas em diferentes espaços geográficos e dimensões socioculturais, econômicas e ambientais. A pesquisa, disseminação e consolidação da cultura, ética, relações interpessoais, domínio de línguas estrangeiras, prospecção mercadológica, marketing e coordenação de equipes são elementos comuns desse eixo. (CNE/CES, 2006, p. 7).

A gastronomia novamente é apresentada como um integrante do contexto da hospitalidade e, embora a menção aos locais de atuação tenha sido abandonada, novamente é enfatizada a necessidade de uma formação ampla, que permita ao egresso exercer atividades correlatas ao planejamento, organização, operação e avaliação de produtos e serviços vinculados às áreas de hospitalidade e lazer em diferentes contextos geográficos e culturais. Na medida em o texto evidencia a importância da "[...] pesquisa, disseminação e consolidação da cultura, ética, relações interpessoais, domínio de línguas estrangeiras, prospecção mercadológica, marketing e coordenação de equipes" (CNE/CES, 2006, p. 7) na atuação destes profissionais, estabelece-se um conjunto de conteúdos e habilidades que devem ser contemplados pelos projetos pedagógicos dos cursos em questão.

\footnotetext{
${ }^{7}$ CES: Câmara de Educação Superior
} 
Outro documento indispensável é o Catálogo Nacional dos Cursos Superiores de Tecnologia, cuja edição de 2010 descreve o perfil do egresso do Curso Superior de Tecnologia da área da seguinte forma:

O tecnólogo em Gastronomia concebe, planeja, gerencia e operacionaliza produções culinárias, atuando nas diferentes fases dos serviços de alimentação, considerando os aspectos culturais, econômicos e sociais. Empresas de hospedagem, restaurantes, clubes, catering, bufês, entre outras, são possibilidades de locais de atuação deste profissional. $\mathbf{0}$ domínio da história dos alimentos, da cultura dos diversos países e da ciência dos ingredientes, além da criatividade e atenção à qualidade são essenciais nesta profissão, em que o alimento é uma arte.(MEC, 2010, p. 44). [grifo nosso].

Este perfil do egresso complementa o conjunto de conteúdos e habilidades que haviam sido indicados no Parecer CNE/CES 2006, aliando conhecimentos de natureza técnica e humanística, expressos na menção aos aspectos culturais, econômicos e sociais que envolvem a atuação deste profissional. A amplitude da formação - concepção, planejamento, gerenciamento e operacionalização de produções culinárias - e dos locais de trabalho também são mencionadas. Ainda, o texto dá uma ênfase culturalista a esta formação profissional, ao mencionar a necessidade do domínio da história dos alimentos ${ }^{8}$ e da cultura dos diversos países ${ }^{9}$ junto ao domínio da ciência alimentar. A menção de que "o alimento é uma arte", parece ter sido inserida para reforçar a ideia de criatividade anteriormente mencionada ${ }^{10}$. Este documento caracteriza ainda a infraestrutura recomendada para a adequada oferta dos cursos, que inclui: uma biblioteca incluindo acervo específico e atualizado, uma cozinha fria e quente, um laboratório de bebidas, um laboratório de informática com programas específicos, um laboratório de panificação e confeitaria e um restaurante didático.

Deve-se mencionar que em 2010 também foi atualizada a CBO2002 - Classificação Brasileira de Ocupações em 2010, criando o subgrupo principal 27 (Profissionais de Gastronomia) e o subgrupo 271 (Profissionais em Gastronomia e Serviços de Alimentação) da Família Ocupacional 2711 (Chefes de Cozinha e afins), já contemplando o profissional com formação superior. O novo texto estabelece: "271105: Chefs de cozinha11 - Chef, Chef de partida, Chef executivo de cozinha. Encarregado de cozinha, Subchef de cozinha, Supervisor de cozinha. 271110 - Tecnólogo em gastronomia - Gastrólogo" (MTE, 2013).

Retomando os documentos da área, verifica-se que as instituições de ensino possuem certa liberdade (respeitadas às características gerais atribuídas aos cursos de tecnologia) para

8 A expressão mais adequada seria "história da alimentação", na medida em que o que é relevante do ponto de vista historiográfico são os processos de cultivo, transformação e consumo destes alimentos.

9 Aqui a menção deveria ser específica à cultura alimentar dos países, e não ao contexto cultural amplo.

10 A afirmação parece ser baseada em senso comum, tendo em vista que há discordância entre estudiosos se a culinária se caracteriza ou não em uma forma de arte, tendo em vista a própria noção acadêmica de arte. Esta e as duas observações anteriores parecem ser fruto de preciosismo acadêmico, mas não o são: é preciso lembrar que se trata de um texto oficial que estabelece parâmetros específicos de uma formação superior.

11 A ocupação de Chefe de Cozinha já existia e era anteriormente registrada sob o código 510125. Com a CBO2010 esse registro anterior foi extinto e um novo foi criado, já associado ao Subgrupo Principal 27 (MTE, 2013). 
conceberem e operacionalizarem seus cursos técnicos em Gastronomia, podendo contemplar, inclusive, demandas mais regionais. Isto, do ponto de vista analítico, acentua a complexidade do tema e a necessidade de pesquisas que ajudem a compreender essa nova realidade. Refletindo sobre os efeitos da formação superior na área de gastronomia, Toledo e Bergamo (2011, p.82) observam:

\begin{abstract}
O Curso Superior de Tecnologia em Gastronomia tem caráter inovador e sintonizado com as necessidades de formação profissional que os cursos tecnológicos representam, sem perder a característica específica de um curso superior de graduação. Este novo ambiente faz emergir nas organizações a necessidade de um profissional mais qualificado, mais flexível e multifuncional, indispensável para o sucesso e, talvez, para a própria sobrevivência das organizações contemporâneas.
\end{abstract}

Analisando este novo cenário, Tomimatsu (2011) observa que é preciso ponderar os diferentes perfis que buscam esta formação, que incluem desde gourmands (apreciadores de gastronomia que não desejam atuar profissionalmente na área), pessoas que já atuam na área e buscam aprimoramento, e pessoas que buscam no curso uma formação que lhe permita ingressar no mercado de trabalho. Outro aspecto que merece atenção é o fato de que a absorção deste novo profissional ainda ocorre de maneira gradual em muitas cidades. Menezes (2011) argumenta que muitas vezes o egresso sofre, inclusive, por conta do desconhecimento por parte da sociedade e do mercado de trabalho das habilidades intelectuais e do preparo propiciado por esta formação. Sobre a questão, Rubim e Rejowski (2012, p.183) observam:

[...] os egressos não são reconhecidos pelo mercado imediatamente como chefs, sendo contratados como ajudantes, no piso da categoria. Isso costuma levar a uma desilusão em relação ao curso e ao mercado, que continua se expandindo, sem poder contar com mãode-obra qualificada de maneira direcional, para suas necessidades mais urgentes que se encontram na base estrutural da carreira, e não apenas no topo, com os chefs de cozinha.

Como Tomimatsu (2011) e Toledo e Bergamo (2011) argumentam, a gastronomia é um campo multidisciplinar em permanente mutação para atender necessidades de mercado constantemente criadas e recriadas. E é para este cenário complexo que os cursos superiores de gastronomia buscam formar profissionais.

\title{
2.1 Panorama das dissertações sobre a formação superior em gastronomia no Brasil
}

As dissertações identificadas no levantamento on line foram caracterizadas a partir dos seguintes elementos: instituições de ensino e programas de pós-graduação em que foram realizadas, palavras-chave, perfil dos pesquisadores (graduação e atuação profissional), objetivos gerais, abrangência da pesquisa, e metodologias utilizadas.

O quadro 1 apresenta o ano de defesa, o título da dissertação e a instituição de ensino superior (IES) onde o trabalho foi desenvolvido: 
Quadro 2 - Dissertações Analisadas - Ano Da Defesa, Título E Instituição

\begin{tabular}{|c|c|c|}
\hline $\begin{array}{l}\text { Ano de } \\
\text { defesa }\end{array}$ & Título do trabalho & Instituição \\
\hline 2005 & $\begin{array}{l}\text { A formação de aluno(as) num curso superior de } \\
\text { Gastronomia: aprendizagem, cultura e cidadania }\end{array}$ & $\begin{array}{l}\text { Universidade Nove de Julho - } \\
\text { UNINOVE }\end{array}$ \\
\hline 2006 & $\begin{array}{l}\text { Ensinando e aprendendo gastronomia: percursos } \\
\text { de formação de professores }\end{array}$ & $\begin{array}{l}\text { Universidade Metodista de } \\
\text { Piracicaba - UNIMEP }\end{array}$ \\
\hline 2008 & $\begin{array}{l}\text { Formação em gastronomia: ingredientes e } \\
\text { temperos de um profissional }\end{array}$ & Universidade Vale do Itajaí - Univali \\
\hline 2009 & As competências do chef de cozinha & $\begin{array}{l}\text { Universidade Anhembi Morumbi - } \\
\text { UAM }\end{array}$ \\
\hline 2010 & $\begin{array}{l}\text { De cozinheiro a gastrônomo: um olhar para } \\
\text { formação do professor em gastronomia }\end{array}$ & $\begin{array}{l}\text { Universidade Cidade de São Paulo - } \\
\text { UNICID }\end{array}$ \\
\hline 2010 & $\begin{array}{l}\text { Formação profissional em gastronomia: um } \\
\text { estudo com os chefes de cozinha na cidade de } \\
\text { João Pessoa (PB) }\end{array}$ & $\begin{array}{l}\text { Universidade Anhembi Morumbi - } \\
\text { UAM }\end{array}$ \\
\hline 2010 & $\begin{array}{l}\text { A formação estética no curso de gastronomia: a } \\
\text { relevância da utilização de filmes nos } \\
\text { procedimentos pedagógicos }\end{array}$ & $\begin{array}{l}\text { Universidade da Cidade de São Paulo } \\
\text { - UNICID }\end{array}$ \\
\hline 2011 & $\begin{array}{l}\text { Tecnologia em gastronomia: um estudo } \\
\text { exploratório dos cursos segundo seus atores }\end{array}$ & $\begin{array}{l}\text { Universidade Anhembi Morumbi - } \\
\text { UAM }\end{array}$ \\
\hline 2012 & $\begin{array}{l}\text { Consumo consciente e ético de alimentos na } \\
\text { formação superior em gastronomia - a realidade e } \\
\text { tendências em cursos de tecnologia no Estado de } \\
\text { São Paulo }\end{array}$ & $\begin{array}{l}\text { Universidade Anhembi Morumbi - } \\
\text { UAM }\end{array}$ \\
\hline
\end{tabular}

Fonte: a autora (2013)

Sete dessas dissertações foram desenvolvidas em IES sediadas na cidade de São Paulo (SP), uma no interior do Estado de São Paulo e uma na cidade de Balneário Camboriu (SC). Esta predominância paulistana nas IES também se repete na abrangência das pesquisas realizadas, já que a maioria foi desenvolvida tendo a cidade de São Paulo como delimitação geográfica (vide quadro 4). Parecem contribuir para esta incidência não apenas a presença dos Programas cursados, mas também a dimensão do segmento de alimentos e bebidas ${ }^{12}$ e a concentração de cursos de formação superior em gastronomia na cidade ${ }^{13}$.

12 Segundo a ABRASEL - Associação Brasileira de Bares, Restaurantes e Similares (2013), a cidade de São Paulo conta com aproximadamente 55 mil estabelecimentos.

13 Segundo dados do E-MEC (2013) , São Paulo possui 12 cursos superiores em Gastronomia em funcionamento, quase $10 \%$ do total de cursos do país. 
Em relação às palavras-chave indicadas, apresentadas no gráfico 1, tem-se seis indicações para 'gastronomia', quatro para 'formação profissional' e duas para 'chef de cozinha', 'mercado de trabalho' e 'formação de professores'. Todas as demais receberam apenas uma indicação. Observa-se que esta análise foi prejudicada pela redundância (como a indicação de 'formação de professores' e ' formação de professores em gastronomia' em um mesmo trabalho), pela escolha de expressões amplas (como 'participação social e educação não formal') e pela indicação de termos que pouco refletem os conteúdo das dissertações (como 'identidade' e 'emancipação').

Gráfico 1 - Palavras-chave indicadas nas dissertações estudadas

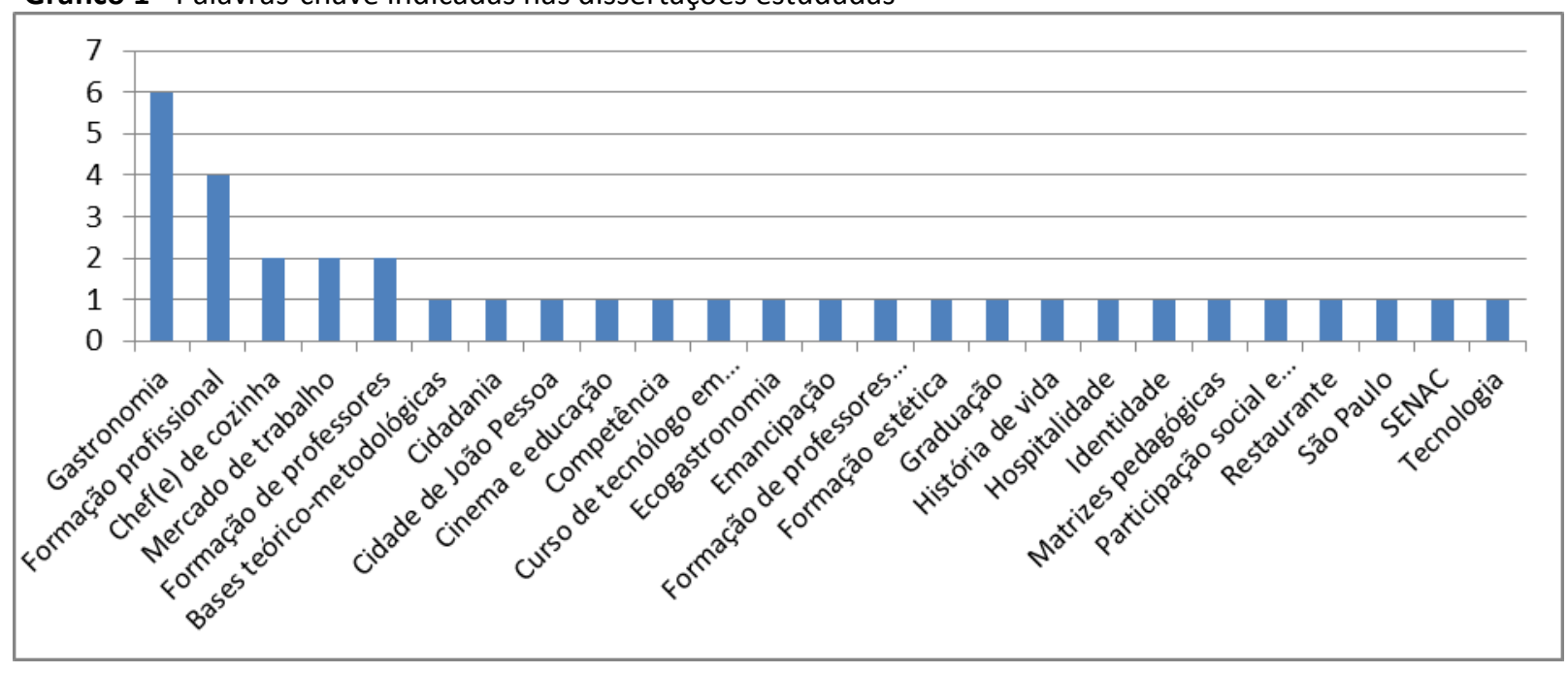

Fonte: a autora (2013)

A alta incidência de 'gastronomia' e 'formação profissional' já era esperada, por conta dos critérios de seleção das dissertações em questão. A preocupação com a atuação profissional do egresso fica evidente nas indicações de 'chef de cozinha' e 'mercado de trabalho'; e a preocupação com o processo de ensino-aprendizagem é tratada por diferentes vieses, com indicações de termos como 'competência', 'matrizes pedagógicas', 'cinema e educação', 'formação de professores', 'bases teórico-metodológicas' e 'formação estética'. Há duas indicações referentes às localidades estudadas (São Paulo e cidade de João Pessoa) e uma indicando uma metodologia empregada (história de vida).

O quadro 3 identifica o perfil do pesquisador em termos de sua formação base e o Programa de Pós-Graduação cursado: 
Quadro 3 - Perfil pesquisador e programa de pós-graduação cursado

\begin{tabular}{|c|c|c|c|}
\hline $\begin{array}{l}\text { Ano } \\
\text { defesa }\end{array}$ & Título do trabalho & $\begin{array}{l}\text { Perfil pesquisador (formação } \\
\text { de base) }\end{array}$ & Programa \\
\hline 2005 & $\begin{array}{l}\text { A formação de aluno(as) num curso } \\
\text { superior de Gastronomia: aprendizagem, } \\
\text { cultura e cidadania }\end{array}$ & $\begin{array}{l}\text { Licenciatura em Matemática, } \\
\text { graduação tecnológica em } \\
\text { Hotelaria, graduação em } \\
\text { Pedagogia }\end{array}$ & $\begin{array}{l}\text { Pós-graduação em } \\
\text { Educação }\end{array}$ \\
\hline 2006 & $\begin{array}{l}\text { Ensinando e aprendendo gastronomia: } \\
\text { percursos de formação de professores }\end{array}$ & $\begin{array}{l}\text { Graduação tecnológica em } \\
\text { Hotelaria }\end{array}$ & $\begin{array}{l}\text { Pós-graduação em } \\
\text { Educação }\end{array}$ \\
\hline 2008 & $\begin{array}{l}\text { Formação em gastronomia: ingredientes e } \\
\text { temperos de um profissional }\end{array}$ & $\begin{array}{l}\text { Graduação em Turismo e } \\
\text { Hotelaria }\end{array}$ & $\begin{array}{l}\text { Pós-graduação em } \\
\text { Turismo e Hotelaria }\end{array}$ \\
\hline 2009 & As competências do chef de cozinha & $\begin{array}{l}\text { Graduação tecnológica em } \\
\text { Gastronomia }\end{array}$ & $\begin{array}{l}\text { Pós-graduação em } \\
\text { Hospitalidade }\end{array}$ \\
\hline 2010 & $\begin{array}{l}\text { De cozinheiro a gastrônomo: um olhar } \\
\text { para formação do professor em } \\
\text { gastronomia }\end{array}$ & $\begin{array}{l}\text { Graduação tecnológica em } \\
\text { Gastronomia }\end{array}$ & $\begin{array}{l}\text { Pós-graduação em } \\
\text { Educação }\end{array}$ \\
\hline 2010 & $\begin{array}{l}\text { Formação profissional em gastronomia: } \\
\text { um estudo com os chefes de cozinha na } \\
\text { cidade de João Pessoa (PB) }\end{array}$ & Graduação em Turismo & $\begin{array}{l}\text { Pós-graduação em } \\
\text { Hospitalidade }\end{array}$ \\
\hline 2010 & $\begin{array}{l}\text { A formação estética no curso de } \\
\text { gastronomia: a relevância da utilização de } \\
\text { filmes nos procedimentos pedagógicos }\end{array}$ & $\begin{array}{l}\text { Graduação em Administração } \\
\text { de empresas }\end{array}$ & $\begin{array}{l}\text { Pós-graduação em } \\
\text { Educação }\end{array}$ \\
\hline 2011 & $\begin{array}{l}\text { Tecnologia em gastronomia: um estudo } \\
\text { exploratório dos cursos segundo seus } \\
\text { atores }\end{array}$ & $\begin{array}{l}\text { Licenciatura em Educação } \\
\text { Física, Graduação Tecnológica } \\
\text { em Gastronomia }\end{array}$ & $\begin{array}{l}\text { Pós-graduação em } \\
\text { Hospitalidade }\end{array}$ \\
\hline 2012 & $\begin{array}{l}\text { Consumo consciente e ético de alimentos } \\
\text { na formação superior em gastronomia - a } \\
\text { realidade e tendências em cursos de } \\
\text { tecnologia no Estado de São Paulo }\end{array}$ & $\begin{array}{l}\text { Graduação tecnológica em } \\
\text { Gastronomia }\end{array}$ & $\begin{array}{l}\text { Pós-graduação em } \\
\text { Hospitalidade }\end{array}$ \\
\hline
\end{tabular}

Fonte: a autora (2013)

A partir da análise do Currículo Lattes dos pesquisadores, observa-se que 4 possuem formação (tecnológica) em Gastronomia e 4 em cursos (tecnológicos e bacharelado) compreendidos no eixo de Hospitalidade: Turismo, Turismo e Hotelaria, Hotelaria, tendo apenas 1 pesquisador cursado Administração de Empresas. A familiaridade dos pesquisadores com o universo da gastronomia e com graduações tecnológicas também fica evidenciado no quadro geral de atuação profissional, apresentado no gráfico 2: 
Gráfico 2 - Atuação profissional do pesquisador durante a realização do mestrado

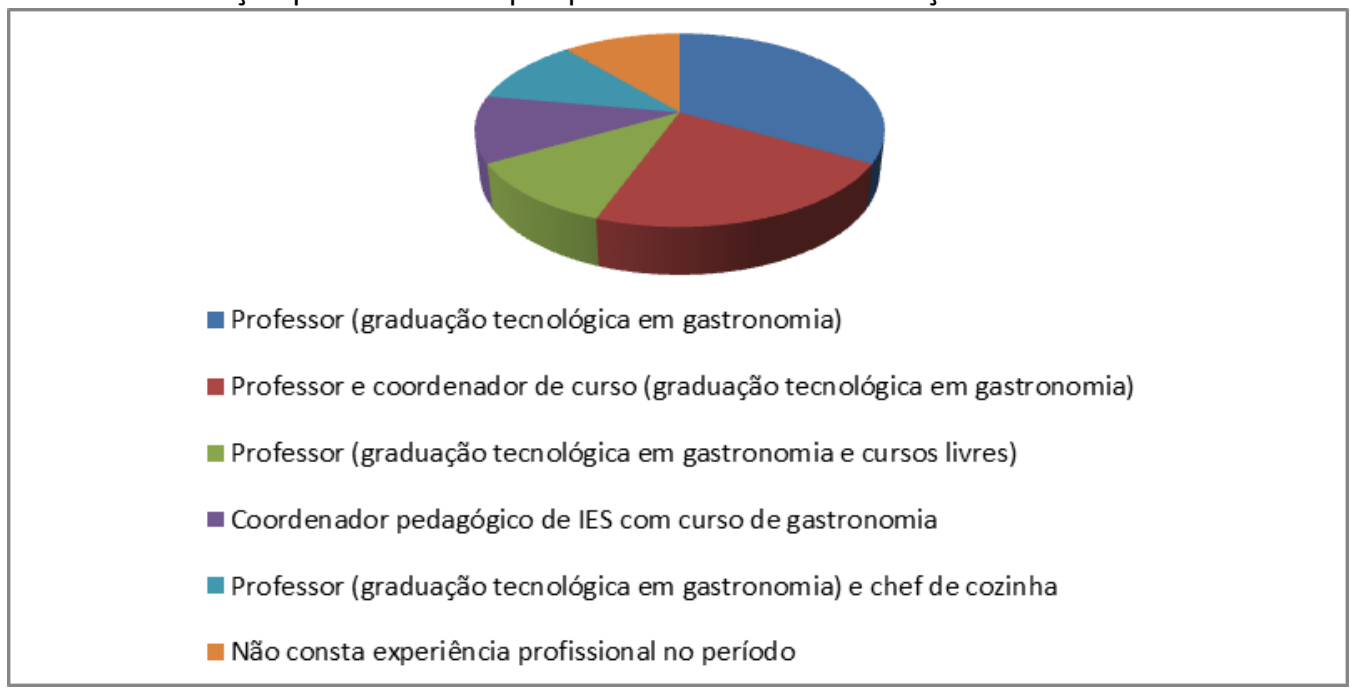

Fonte: a autora (2014)

Observa-se que dois pesquisadores exerciam o cargo de coordenadores de cursos de graduação tecnológica em gastronomia. Ao todo, somando-se aqueles que também exerciam outras funções, 7 dos 9 pesquisadores atuavam como professores em cursos tecnológicos em gastronomia. Estes dados permitem inferir que provavelmente as problemáticas pesquisadas surgiram da observação direta do cotidiano de trabalho ou de inquietações despertadas ainda no período de realização da graduação. Ainda, este movimento em busca de uma pós-graduação stricto sensu parece ser reflexo da própria expansão da oferta de cursos superiores de Gastronomia: na medida em que o número de cursos cresceu, cresceu também a necessidade de um corpo docente qualificado, que não tenha apenas conhecimentos práticos, mas também titulação compatível com as exigências do mundo universitário.

Retomando a análise do quadro 3, observa-se que não foram levantadas as áreas de concentração nem as linhas de pesquisa em que tais dissertações se inserem, mas deve-se observar que 4 pesquisadores buscaram Programas de Pós-Graduação em Educação para desenvolverem suas pesquisas; 4 procuraram um Programa de Pós-Graduação em Hospitalidade e 1 pesquisador desenvolveu seu trabalho em um Programa de Pós-Graduação em Turismo e Hotelaria. A abordagem pedagógica-educacional é óbvia, tendo em vista a discussão centrada na formação acadêmica voltada para o mercado de trabalho. A opção pelos demais programas parece ser fruto da afinidade temática entre as áreas de Hospitalidade e Gastronomia, e Turismo e Hotelaria e Gastronomia.

O quadro 4 identifica os objetivos gerais e a abrangência das pesquisas realizadas: 
Quadro 4 - Objetivos gerais da dissertação das dissertações de mestrado e abrangência da pesquisa

\begin{tabular}{|c|c|c|c|}
\hline $\begin{array}{l}\text { Ano } \\
\text { defesa }\end{array}$ & Título do trabalho & Objetivos gerais & $\begin{array}{l}\text { Abrangência da } \\
\text { Pesquisa }\end{array}$ \\
\hline 2005 & $\begin{array}{l}\text { A formação de aluno(as) num curso } \\
\text { superior de Gastronomia: } \\
\text { aprendizagem, cultura e cidadania }\end{array}$ & $\begin{array}{l}\text { Realizar um estudo sobre o processo de } \\
\text { formação dos alunos de um curso superior } \\
\text { tecnológico em Gastronomia. }\end{array}$ & $\begin{array}{l}\text { Uma (01) Instituição } \\
\text { de ensino, na cidade } \\
\text { de São Paulo (SP) }\end{array}$ \\
\hline 2006 & $\begin{array}{l}\text { Ensinando e aprendendo gastronomia: } \\
\text { percursos de formação de professores }\end{array}$ & $\begin{array}{l}\text { Conhecer que saberes os professores de } \\
\text { prática, sem formação específica para } \\
\text { docência, mobilizam para ensinar em um } \\
\text { curso de graduação tecnológica em } \\
\text { Gastronomia. }\end{array}$ & $\begin{array}{l}\text { Uma (01) Instituição } \\
\text { de Ensino, na cidade } \\
\text { Águas de São Pedro } \\
\text { (SP) }\end{array}$ \\
\hline 2008 & $\begin{array}{l}\text { Formação em gastronomia: } \\
\text { ingredientes e temperos de um } \\
\text { profissional }\end{array}$ & $\begin{array}{l}\text { Analisar as bases teórico-metodológicas que } \\
\text { fundamentam a formação profissional em } \\
\text { gastronomia nas instituições de ensino } \\
\text { superior catarinenses }\end{array}$ & $\begin{array}{l}\text { Quatro (04) cursos } \\
\text { tecnológicos de } \\
\text { Gastronomia do } \\
\text { Estado de Santa } \\
\text { Catarina. }\end{array}$ \\
\hline 2009 & As competências do chef de cozinha & $\begin{array}{l}\text { Identificar as competências mais importantes } \\
\text { para a formação de um chef de cozinha a } \\
\text { partir da vivência profissional de chefs em } \\
\text { atuação na capital de São Paulo. }\end{array}$ & $\begin{array}{l}\text { Cidade de São Paulo } \\
\text { (SP) }\end{array}$ \\
\hline 2010 & $\begin{array}{l}\text { De cozinheiro a gastrônomo: um olhar } \\
\text { para formação do professor em } \\
\text { gastronomia }\end{array}$ & $\begin{array}{l}\text { Traçar um panorama sobre a formação de } \\
\text { professores atuantes no curso superior de } \\
\text { tecnologia em gastronomia. Investigar os } \\
\text { saberes que os professores mobilizam para } \\
\text { formar gastrônomos e como os professores } \\
\text { de gastronomia têm tido acesso a esses } \\
\text { saberes. }\end{array}$ & $\begin{array}{l}\text { Cidade de São Paulo } \\
\text { (SP) }\end{array}$ \\
\hline 2010 & $\begin{array}{l}\text { Formação profissional em } \\
\text { gastronomia: um estudo com os chefes } \\
\text { de cozinha na cidade de João Pessoa } \\
\text { (PB) }\end{array}$ & $\begin{array}{l}\text { Avaliar a formação dos profissionais chefes } \\
\text { de cozinha da cidade de João Pessoa, } \\
\text { levando-se em consideração,principalmente, } \\
\text { aspectos ligados à origem e ao histórico } \\
\text { profissional que os levaram a escolher essa } \\
\text { profissão. }\end{array}$ & $\begin{array}{l}\text { Cidade de João } \\
\text { Pessoa (PB) }\end{array}$ \\
\hline 2010 & $\begin{array}{l}\text { A formação estética no curso de } \\
\text { gastronomia: a relevância da utilização } \\
\text { de filmes nos procedimentos } \\
\text { pedagógicos }\end{array}$ & $\begin{array}{l}\text { Investigar a relevância do cinema na } \\
\text { formação profissional e humana dos alunos } \\
\text { dos cursos de gastronomia. }\end{array}$ & $\begin{array}{l}\text { Um (01) filme, } \\
\text { Ratatouille (2007). }\end{array}$ \\
\hline 2011 & $\begin{array}{l}\text { Tecnologia em gastronomia: um } \\
\text { estudo exploratório dos cursos } \\
\text { segundo seus atores }\end{array}$ & $\begin{array}{l}\text { Investigar e avaliar, por meio de diferentes } \\
\text { atores, se os cursos oferecidos pelas } \\
\text { Universidades apresentam-se alinhados aos } \\
\text { interesses diretamente envolvidos na } \\
\text { graduação tecnológica em gastronomia. }\end{array}$ & $\begin{array}{l}\text { Cidade de São Paulo } \\
\text { (SP), não especifica } \\
\text { o número de cursos } \\
\text { envolvidos. }\end{array}$ \\
\hline 2012 & $\begin{array}{l}\text { Consumo consciente e ético de } \\
\text { alimentos na formação superior em } \\
\text { gastronomia - a realidade e tendências } \\
\text { em cursos de tecnologia no Estado de } \\
\text { São Paulo }\end{array}$ & $\begin{array}{l}\text { Investigar a preocupação com o consumo } \\
\text { consciente e ético de alimentos como uma } \\
\text { realidade e/ou uma tendência em cursos de } \\
\text { Tecnologia em Gastronomia no estado de São } \\
\text { Paulo, Brasil, a partir de suas propostas } \\
\text { formativas e da visão de seus coordenadores. }\end{array}$ & Estado de São Paulo. \\
\hline
\end{tabular}

Fonte: A autora (2013)

Como pré-requisito desta pesquisa, todas as dissertações selecionadas tratam da questão da formação profissional. As pesquisas dizem respeito basicamente ao processo de ensino- 
aprendizagem: 2 dissertações desenvolvem o tema sob o prisma do perfil dos professores do curso, com destaque para aqueles dedicados às disciplinas práticas (estes trabalhos inclusive possuem objetivos e estruturas muito semelhantes); 1 analisa a trajetória de formação dos alunos em um curso tecnológico de gastronomia; 1 analisa a compatibilidade entre os preceitos da educação tecnológica e a realidade de formação ofertada por cursos; 1 analisou as bases teóricometodológicas que fundamentam a concepção de cursos tecnológicos de Gastronomia; 1 trabalho analisou a existência de práticas e conteúdos relacionados ao consumo consciente nos currículos de cursos tecnológicos de Gastronomia; e 1 o uso de filmes como ferramenta pedagógica de formação estética nos cursos tecnológicos de Gastronomia (embora, na verdade, a pesquisa tenha se fixado um filme específico, deixando em segundo plano a análise da formação superior em gastronomia). Ainda, 3 dissertações tratam do processo ensino-aprendizagem face a inserção do futuro profissional no mercado de trabalho (baseando-se nas percepções sobre o mercado de trabalho e na trajetória de profissionais consolidados para refletir sobre as necessidades da formação superior em gastronomia). Em termos de abrangência da pesquisa, verifica-se a já comentada incidência de pesquisas realizadas em São Paulo.

O quadro 5 apresenta a metodologia utilizada:

Quadro 5 - Metodologias utilizadas nas dissertações analisadas

\begin{tabular}{|c|c|c|}
\hline $\begin{array}{l}\text { Ano } \\
\text { defesa }\end{array}$ & Título do trabalho & Metodologia utilizada \\
\hline 2005 & $\begin{array}{l}\text { A formação de alunos(as) } \\
\text { num curso superior de } \\
\text { Gastronomia: } \\
\text { aprendizagem, cultura e } \\
\text { cidadania }\end{array}$ & $\begin{array}{l}\text { Revisão bibliográfica e pesquisa de campo dividida em } 3 \text { etapas. A primeira, } \\
\text { de caráter quantitativo, envolveu a aplicação de questionários para conhecer } \\
\text { e analisar o perfil socioeconômico dos candidatos ao processo seletivo para o } \\
\text { curso superior de tecnologia em Gastronomia ( } 124 \text { respondentes). A segunda } \\
\text { etapa, de caráter qualitativo envolveu a realização de entrevistas com alunos } \\
\text { buscando identificar as representações que os alunos tem do mercado de } \\
\text { trabalho, da formação que recebem, de sua trajetória de vida e vivência } \\
\text { cotidiana ( } 24 \text { entrevistados, escolhidos aleatoriamente). Terceira etapa, de } \\
\text { caráter qualitativo, consistiu na análise de autobiografias dos alunos para } \\
\text { analisar suas origens familiares, tradições e culturas ( } 17 \text { respondentes). }\end{array}$ \\
\hline 2006 & $\begin{array}{l}\text { Ensinando e aprendendo } \\
\text { gastronomia: percursos } \\
\text { de formação de } \\
\text { professores }\end{array}$ & $\begin{array}{l}\text { Revisão bibliográfica e pesquisa de campo. Primeira etapa: identificação junto } \\
\text { aos alunos dos melhores professores de disciplinas práticas. Esta etapa tinha } \\
\text { como universo } 193 \text { alunos, foi realizada uma amostragem com } 53 \text { alunos } \\
\text { (concluintes do curso em questão) e ao final verificou-se } 46 \text { respondentes. Na } \\
\text { segunda etapa, os dois professores mais votados foram entrevistados a partir } \\
\text { de um roteiro semi-estruturado, que teve como objetivo conhecer suas } \\
\text { trajetórias de vida e sua constituição como professores. }\end{array}$ \\
\hline 2008 & $\begin{array}{l}\text { Formação em } \\
\text { gastronomia: } \\
\text { ingredientes e temperos } \\
\text { de um profissional }\end{array}$ & $\begin{array}{l}\text { Revisão bibliográfica e pesquisa documental, focada principalmente na } \\
\text { análise dos programas das disciplinas de cursos de Gastronomia do Estado de } \\
\text { Santa Catarina ( } 4 \text { cursos analisados). }\end{array}$ \\
\hline
\end{tabular}


Quadro 5 - Metodologias utilizadas nas dissertações analisadas

(conclusão)

\begin{tabular}{|c|c|c|}
\hline 2009 & $\begin{array}{l}\text { As competências do chef } \\
\text { de cozinha }\end{array}$ & $\begin{array}{l}\text { Revisão bibliográfica e pesquisa de campo, realizada por meio de um } \\
\text { questionário organizado em três sessões: a primeira destinada ao perfil sócio- } \\
\text { profissional do chef de cozinha, a segunda para a identificação dos mais } \\
\text { importantes conhecimentos, habilidades e atitudes necessárias para o } \\
\text { desempenho deste papel e a terceira sessão destinada à importância da } \\
\text { definição das competências deste profissional. A análise dos dados ocorreu } \\
\text { de forma quantitativa e qualitativa ( } 8 \text { respondentes). }\end{array}$ \\
\hline 2010 & $\begin{array}{lr}\text { De cozinheiro } & \text { a } \\
\text { gastrônomo: um } & \text { olhar } \\
\text { para formação } & \text { do } \\
\text { professor } & \text { em } \\
\text { gastronomia }\end{array}$ & $\begin{array}{l}\text { Revisão bibliográfica e realização de entrevistas reflexivas com professores } \\
\text { atuantes no curso de } \\
\text { gastronomia de Instituições de Ensino Superior na cidade de São Paulo que } \\
\text { também transitam ou já transitaram pelo mercado de trabalho específico da } \\
\text { área da hospitalidade ( } 4 \text { entrevistados). }\end{array}$ \\
\hline 2010 & $\begin{array}{l}\text { Formação profissional } \\
\text { em gastronomia: um } \\
\text { estudo com os chefes de } \\
\text { cozinha na cidade de } \\
\text { João Pessoa (PB) }\end{array}$ & $\begin{array}{l}\text { Pesquisa descritiva utilizando-se de métodos exploratórios de caráter } \\
\text { qualitativo, desenvolvida meio da aplicação de entrevistas semiestruturadas, } \\
\text { com profissionais chefes de cozinha selecionados a partir de critérios de } \\
\text { amostragem não probabilísticos por julgamento (8 entrevistados). }\end{array}$ \\
\hline 2010 & $\begin{array}{l}\text { A formação estética no } \\
\text { curso de gastronomia: a } \\
\text { relevância da utilização } \\
\text { de filmes nos } \\
\text { procedimentos } \\
\text { pedagógicos }\end{array}$ & $\begin{array}{l}\text { Revisão bibliográfica e análise documental, que abrange documentos teóricos } \\
\text { e filmes propícios aos conteúdos dos cursos de gastronomia.De maneira } \\
\text { específica, o autor analisa o filme Ratatouille (2007). }\end{array}$ \\
\hline 2011 & $\begin{array}{l}\text { Tecnologia em } \\
\text { gastronomia: um estudo } \\
\text { exploratório dos cursos } \\
\text { segundo seus atores }\end{array}$ & $\begin{array}{l}\text { Pesquisa de caráter exploratório, com revisão bibliográfica e pesquisa de } \\
\text { campo organizada da seguinte maneira:aplicação de questionários com } \\
\text { discentes de duas Instituições de ensino ( } 34 \text { respondentes); aplicação de } \\
\text { questionário semi-estruturado com coordenadores de curso ( } 8 \\
\text { respondentes); aplicação de questionário semi-estruturado com docentes de } \\
\text { duas Instituições de ensino ( } 11 \text { respondentes) e entrevistas com } \\
\text { empregadores na área de gastronomia ( } 5 \text { entrevistados). }\end{array}$ \\
\hline 2012 & $\begin{array}{l}\text { Consumo consciente } \text { e } \\
\text { ético de alimentos na } \\
\text { formação superior em } \\
\text { gastronomia } \quad-\quad r \\
\text { realidade e tendências } \\
\text { em cursos de tecnologia } \\
\text { no Estado de São Paulo }\end{array}$ & $\begin{array}{l}\text { Pesquisa exploratório-descritiva, desenvolvida por meio de revisão } \\
\text { bibliográfica e documentos e informações disponíveis nos sites de } 11 \\
\text { instituições que ofertam } 19 \text { cursos no estado de São Paulo, e por meio de } \\
\text { entrevistas semiestruturadas aplicada aos coordenadores destes mesmos } \\
\text { cursos (11 respondentes) }\end{array}$ \\
\hline
\end{tabular}

Fonte: a autora (2013)

É preciso mencionar que nem todas as dissertações apresentaram um descritivo metodológico consistente. Todas as pesquisas analisadas tiveram caráter qualitativo, e mesmo as que incluíam análises quantitativas não apresentaram dados que demandassem/viabilizassem um tratamento quantitativo mais acurado (algumas amostras foram pequenas e muitas vezes a dimensão do universo, o cálculo da amostragem e o indicativo de margem de erro não foram 
apresentados). Todos os autores realizaram revisão bibliográfica, mesmo aqueles que não mencionaram este procedimento, 2 autores realizaram também pesquisas documentais e 7 realizaram algum tipo de consulta aos sujeitos envolvidos no universo de formação e atuação profissional em gastronomia. Neste último caso, 2 pesquisas consultaram chefs; 1 coordenadores de curso; 1 candidatos ao processo seletivo e alunos em curso; 1 apenas professores, 1 professores e alunos do curso estudado; 1 alunos, professores, coordenadores e empregadores. Os instrumentos de coleta de dados mais utilizados foram roteiro de entrevistas (em 6 trabalhos), questionários ( 3 trabalhos) e autobiografia (1 trabalho), observando que 2 trabalhos utilizaram mais de uma modalidade. As entrevistas semiestruturadas predominam com 4 ocorrências, havendo 1 menção para entrevista reflexiva e 1 formato de entrevista não especificado. A maioria das pesquisas que utilizaram entrevistas, contudo, não especificou os parâmetros de análise das informações coletadas.

\section{CONSIDERAÇÕES FINAIS}

Os dados apresentados neste artigo permitem vislumbrar o quadro atual das pesquisas realizadas em nível de pós-graduação (mestrado) até 2012. A partir dessa breve análise, é possível observar que a maioria das pesquisas estudadas foram realizadas na cidade de São Paulo; que os pesquisadores possuem familiaridade com os cursos de graduação tecnológica em gastronomia tanto do ponto de vista da formação acadêmica quanto da atuação profissional -; e a maioria das pesquisas dizem respeito ao desenvolvimento do processo de ensino-aprendizagem, ficando a análise do processo ensino-aprendizagem face a inserção do futuro profissional no mercado de trabalho em segundo plano.

Considerando os objetivos gerais, verifica-se que a maioria das pesquisas terminou por desenvolver estudos de caso, mesmo que esta perspectiva não tenha sido assumida no descritivo metodológico. No que se refere à metodologia, é preciso observar que alguns trabalhos apresentaram descritivos metodológicos por demais sucintos, que não elucidam o dimensionamento da amostra ou as formas com que os dados coletados foram tratados. A seleção das palavras-chave também mostrou-se irregular, com alguns trabalhos apresentando indicações que não correspondiam diretamente ao conteúdo do trabalho desenvolvido.

Verifica-se ainda que estes trabalhos parecem atender duas necessidades criadas pela expansão do ensino superior em Gastronomia: a de compreensão desta nova realidade e também a demanda por profissionais pós-graduados pelas instituições de ensino superior que decidiram investir na área. Ainda, é preciso ponderar que há poucas pesquisas publicadas sobre a temática, o que evidencia o caráter pioneiro destas dissertações e todos os desafios e dificuldades trazidas por este pioneirismo. Os efeitos da expansão da formação superior em gastronomia no mercado de trabalho e na própria concepção dos cursos são relativamente recentes e ainda não podem ser mensurados de forma mais aprofundada. Tem-se então todo um panorama aberto a novas pesquisas. 


\section{REFERÊNCIAS}

ABRASEL. (2013). Números de São Paulo. Disponível em: http://www.sp.abrasel.com.br/index.php/noticias Acesso em: 15.abr.2013.

CNE/CES. (2001). Parecer n. 436/2001, aprovado em 2 de abril de 2001. Disponível em: http://portal.mec.gov.br/cne/arquivos/pdf/CES0436.pdf Acesso em: 04.abr.2013.

CNE/CP. (2002a). Parecer n. 29/2002, aprovado em 3 de dezembro de 2002. Disponível em: http://portal.mec.gov.br/cne/arquivos/pdf/cp29.pdf. Acesso em: 04.abr.2013.

CNE/CP (2002b). Resolução n. 3/2002, aprovada em 18 de dezembro de 2002. Disponível em: http://portal.mec.gov.br/cne/arquivos/pdf/CP032002.pdf Acesso em: 04.abr.2013.

CNE/CP. (2006). Parecer n. 6/2006, aprovado em 6 de abril de 2006. Disponível em: http://portal.mec.gov.br/cne/arquivos/pdf/pcp006 06.pdf. Acesso em: 04.abr.2013.

CNE/CES. (2006). Parecer n. 277/2006, aprovado em 7 de dezembro de 2006. Disponível em: http://portal.mec.gov.br/cne/arquivos/pdf/pces277 06.pdf Acesso em: 04.abr.2013.

CNE/CES. (2008a). Parecer n. 19/2008, aprovado em 31 de janeiro de 2008. Disponível em: http://portal.mec.gov.br/cne/arquivos/pdf/pces019 08.pdf Acesso em: 04.abr.2013.

CNE/CES. (2008b). Parecer n. 239/2008, aprovado em 06 de novembro de 2008. Disponível em: http://portal.mec.gov.br/cne/arquivos/pdf/pces239 08.pdf Acesso em: 04.abr.2013.

E-MEC. (2013). Listagem dos cursos superiores de Gastronomia no país. Disponível em: http://emec.mec.gov.br/ Acesso em: Acesso em 25.abr.2013.

Kissmann, H.; Rocha, L. (2008). Diploma de chef - onde estudar. Disponível em: http://prazeresdamesa.uol.com.br/diploma-de-chef-onde-estudar/ Acesso em 20.abr.2013.

Lima, J. R.; Rejowski, M. (2011). Ensino superior em turismo no Brasil: a produção acadêmica de dissertações e teses (2000-2009). Revista Brasileira de Pesquisa em Turismo, v.5 (3). Disponível em: http://rbtur.org.br/rbtur/article/view/462/484 Acesso em: 30.abr.2013.

MEC. (2010) Catálogo nacional dos cursos superiores de tecnologia. Disponível em: http://portaldoprofessor.mec.gov.br/storage/materiais/0000009402.PDF. Acesso em 10.abr. 2013.

Meneses, M. C. P. (2011). A preparação e o encaminhamento ao mercado de trabalho. Tomimatsu, C. E.; Furtado, S. M. (orgs). Formação em gastronomia. Boccato: São Paulo, p.49-71.

MTUR. (2010). Cadastro Brasileiro de ocupações. Disponível em:

http://www3.mte.gov.br/pdet/ajuda/notas comunic/comu16510.asp Acesso em 08.abr.2013.

Rejowski, M. (2010). Caracterização da produção científica sobre Turismo no Brasil - estudo documental das teses de doutorado (1990-2005). Anais do VII Seminário da ANPTUR. Disponível em:

http://www.anptur.org.br/novo portal/anais anptur/anais 2010/arquivos/caracterizacao da producao c ientifica sobre.pdf Acesso em: 30.abr.2013. 
Rubim, R. E.; Rejowski, M. (2013). O ensino superior da gastronomia no Brasil: análise da regulamentação, da distribuição e do perfil geral da formação (2010-2012). Revista Turismo Visão e Ação, v.15, n. 2, p. 166184, mai-ago.

Toledo, R. F. M.; Bergamo, M. (2011). O currículo gastronômico: um universo a ser explorado. Tomimatsu, C. E.; Furtado, S. M. (orgs). Formação em gastronomia. Boccato: São Paulo, 2011, p.72-86.

Tomimatsu, C. E. (2011). Um cardápio chamado carreira. Tomimatsu, C. E.; Furtado, S. M. (orgs). Formação em gastronomia. Boccato: São Paulo, p. 29-48.

\section{Dissertações analisadas:}

Belculfine, M. N. (2011). Tecnologia em gastronomia: um estudo exploratório dos cursos segundo seus atores. Programa de Pós-Graduação (Mestrado) em Hospitalidade. Universidade Anhembi Morumbi, São Paulo. 110p.

Domingues, J. (2008). Formação em gastronomia: ingredientes e temperos de um profissional. Programa de Pós-Graduação (Mestrado) em Turismo e Hotelaria. Universidade do Vale do Itajaí, Balneário Camboriú. 160 .

Lima, T. P. A. (2010). Formação profissional em gastronomia: um estudo com os chefes de cozinha na cidade de João Pessoa (PB). Programa de Pós-Graduação (Mestrado) em Hospitalidade. Universidade Anhembi Morumbi, São Paulo.111p.

Menezes, M. C. P. (2005). A formação de aluno(as) num curso superior de Gastronomia: aprendizagem, cultura e cidadania. Programa de Pós-Graduação (Mestrado) em Educação. Universidade Nove de Julho, São Paulo. 210p.

Miyazaki, M. H. (2006). Ensinando e aprendendo gastronomia: percursos de formação de professores. Programa de Pós-Graduação (Mestrado) em Educação. Universidade Metodista de Piracicaba, Piracicaba. $115 p$.

Rubim, R. E. (2012). Consumo consciente e ético de alimentos na formação superior em gastronomia realidade e tendências em cursos de tecnologia no Estado de São Paulo. Programa de Pós-Graduação (Mestrado) em Hospitalidade. Universidade Anhembi-Morumbi, São Paulo. 216p.

Schwan, T. P. (2009). As competências do chef de cozinha. Programa de Pós-Graduação (Mestrado) em Hospitalidade. Universidade Anhembi Morumbi, São Paulo. 97p.

Toledo, R. F. M. (2010). De cozinheiro a gastrônomo: um olhar para formação do professor em gastronomia. Programa de Pós-Graduação (Mestrado) em Educação. Universidade da Cidade de São Paulo, São Paulo. 105p.

Venâncio, A. (2010). A formação estética no curso de gastronomia: a relevância da utilização de filmes nos procedimentos pedagógicos. Programa de Pós-Graduação (Mestrado) em Educação. Universidade da Cidade de São Paulo, São Paulo. 135p. 